\title{
MICROPROPAGAÇÃO DE VIOLETA-AFRICANA (Saintpaulia ionantha Wendl.): EFEITO DA BENZILAMINOPURINA NA MULTIPLICAÇÃO
}

\author{
Micropropagation of African-Violet (Saintpaulia ionantha Wendl.): \\ Effect of Benzylaminopurine on multiplication
}

\author{
Marco Antônio Karam Lucas ${ }^{1}$, Joelma Dutra Fagundes², Denise Dias Pereira ${ }^{1}$, \\ Marcelo Benevenga Sarmento ${ }^{3}$
}

\begin{abstract}
RESUMO
A violeta-africana (Saintpaulia ionantha Wendl.) é uma espécie cultivada como ornamental pela beleza de suas flores e folhagem. A Benzilaminopurina (BAP) pode ser utilizada na multiplicação in vitro dessa espécie, no entanto, inexistem informações mais detalhadas sobre as respostas obtidas sobre a multiplicação, em uma faixa ampla de concentrações. Objetivou-se com este trabalho determinar o efeito do BAP na multiplicação in vitro de violeta-africana. Foram utilizados, como explantes, tufos de brotações das cultivares Optimara Miki, Optimara Maki e Optimara Akemi, com tamanhos entre 0,8 e 2,0 cm. Empregou-se o meio MS, com concentrações de nutrientes minerais e vitaminas reduzidas à metade, suplementado com mio-inositol $\left(100 \mathrm{mg} \mathrm{L}^{-1}\right)$, sacarose $\left(30 \mathrm{~g} \mathrm{~L}^{-1}\right)$ e ágar $\left(7 \mathrm{~g} \mathrm{~L}^{-1}\right)$. Os tratamentos utilizados foram: 0,$0 ; 0,44 ; 1,78 ; 3,08 \mathrm{e} \mathrm{4,44} \mathrm{mM} \mathrm{de} \mathrm{BAP.} \mathrm{O} \mathrm{pH} \mathrm{do} \mathrm{meio} \mathrm{foi} \mathrm{ajustado} \mathrm{para}$ 5,8 antes da esterilização. O material vegetal permaneceu em temperatura de $24 \pm 2{ }^{\circ} \mathrm{C}$, fotoperíodo de 14 horas e densidade de fluxo luminoso de $40 \mathrm{mmol} \mathrm{c}^{4} \mathrm{~m}^{-2} \mathrm{~s}^{-1}$. As avaliações do número total de brotações e do número e altura de brotações maiores que $3 \mathrm{~mm}$ foram realizadas aos 46 dias. A adição de BAP ao meio de cultura foi essencial para a multiplicação das culturas. As respostas aos tratamentos variaram entre os genótipos utilizados. Maiores resultados de número total de brotações e número de brotações superiores que três milímetros foram observados em concentrações de BAP situadas entre 1,78 e 4,44 mM. A altura das brotações decresceu com a utilização de BAP.
\end{abstract}

Termos para indexação: Saintpaulia ionantha, BAP, cultura de tecidos.

\section{ABSTRACT}

African-Violet (Saintpaulia ionantha Wendl.) is an ornamental plant widely cultivated, because of its beautiful foliage and flowers. Benzylaminopurine (BAP) can be used to violet multiplication, but there weren't information about results with several concentrations. The aim of this work was to determine the effect of different concentrations of BAP on the multiplication of violet cultures. One utilized, as explants, shoot clusters of cultivars Optimara Miki, Optimara Maki e Optimara Akemfrom, with height from 0,8 to $2,0 \mathrm{~cm}$. One utilized MS medium, with half concentration of mineral nutrients and vitamins, suplementated with myoinositol $\left(100 \mathrm{mg} \mathrm{L}^{-1}\right)$, sucrose $\left(30 \mathrm{~g} \mathrm{~L}^{-1}\right)$ and agar $\left(7 \mathrm{~g} \mathrm{~L}^{-1}\right)$. The treatments applied were: $0.0,0.44,1.78,3,08 \mathrm{e} 4,44 \mathrm{mM}$ of BAP. The $\mathrm{pH}$ of the medium was adjusted to 5,8 before sterilization. Cultures remained at $24 \pm 2{ }^{\circ} \mathrm{C}$, photoperiod of 14 hours and $40 \mathrm{mmol} \mathrm{cm}$ ${ }^{2} \mathrm{~s}^{-1}$ of light density flux. Total shoot number and number and height of shoots with more than three millimeters were evaluated at 46 days. Addition of BAP to the culture medium was essential to multiplication of cultures. Responses of treatments varied between cultivars. Best results of total shoot number and number shoots with more than three millimeters were found with concentrations between 1.78 e $4.44 \mathrm{mM}$. The height of shoots decreased with the addition of BAP.

Index terms: Saintpaulia ionantha, BAP, tissue culture.

\section{(Recebido em 6 de junho de 2006 e aprovado em 2 de maio de 2007)}

\section{INTRODUÇÃO}

A floricultura, em seu sentido amplo, abrange o cultivo de plantas ornamentais, desde flores de corte até plantas envasadas. Trabalha com uma grande diversidade de espécies, entre elas a violeta-africana, muito difundida comercialmente e utilizada para decorar ambientes (TOMBOLATO et al., 1987).

Sua propagação pode ser realizada por métodos convencionais ou por cultivo in vitro. A cultura de tecidos in vitro consiste no cultivo de partes do vegetal num meio de cultura definido, sob condições ambientais e assépticas controladas. A utilização da micropropagação para produção de plantas de violeta-africana apresenta como vantagens a alta taxa de multiplicação (TAKEBAYASHI, 1987) e a obtenção de plantas vigorosas, isentas de doenças, que apresentam boa qualidade fitossanitária (MACIEL et al., 2000).

\footnotetext{
Engenheiros Agrônomos, Mestres - Instituto Biotecnológico de Reprodução Vegetal/INTEC - Universidade da Região da Campanha/URCAMP - Rua Flores da Cunha, 310, Centro - 96400-350 - Bagé, RS - marcoantoniolucas@yahoo.com.br; ddpereira@yahoo.com.br

2Bióloga - Rua Paul Harris, 05, Centro - 97015-480 - Santa Maria, RS - jdf 82@hotmail.com

${ }^{3}$ Engenherio Agrônomo, Mestre - Curso de Ciências Biológicas - Universidade da Região da Campanha/URCAMP - Rua Flores da Cunha, 310 , Centro 36400-350 - Bagé, RS - marcelos@alternet.com.br
} 
O processo de micropropagação de plantas envolve a realização de quatro etapas básicas: o estabelecimento e a iniciação de culturas, a multiplicação, o enraizamento e a aclimatização de plantas (GRATTAPAGLIA \& MACHADO, 1998). O sucesso nessas etapas depende do controle de um grande número de variáveis, entre elas a composição do meio de cultura.

Os reguladores de crescimento possuem papel importante na coordenação do crescimento e do desenvolvimento vegetal, controlando muitos processos bioquímicos e fisiológicos (HARTMANN et al., 1988). Muitas das respostas induzidas pelos hormônios envolvem a morfogênese dos vegetais (HUGHES, 1978), através da indução ou da inibição de etapas do ciclo celular. O resultado de sua ação está diretamente relacionado com o tipo, concentração, combinação entre reguladores exógenos utilizados e sua interação com os níveis endógenos de hormônios (CALDAS et al., 1998; DORNELLES \& PETERS, 1993).

As citocininas são uma classe de reguladores de crescimento com capacidade marcante de induzir a divisão celular em tecidos vegetais. Portanto, são importantes para formação de órgãos, principalmente, aéreos. A Benzylaminopurina (BAP) é uma citocinina sintética utilizada para a multiplicação in vitro.

Alguns trabalhos citam a utilização de BAP na multiplicação de violeta-africana em concentrações que variam de 2,22 a 4,44 mM (MACIEL et al., 2000; SUNPUI \& KANCHANAPOOM, 2002; TOMBOLATO et al., 1995). Entretanto, não foram realizados ensaios avaliando-se o efeito de diferentes concentrações de BAP, na etapa de multiplicação. Assim, objetivou-se determinar a curva de resposta de multiplicação nessa espécie, em função de diferentes concentrações de BAP.

\section{MATERIAL E MÉTODOS}

Foram utilizados como explantes, tufos de brotações das cultivares de violeta-africana Optimara Miki, Optimara Maki e Optimara Akemi, com comprimento entre 0,8 e 2,0 cm, obtidos na segunda multiplicação in vitro, em meio de cultura MS (MURASHIGE \& SKOOG, 1962), suplementado com sacarose $\left(30 \mathrm{~g} \mathrm{~L}^{-1}\right)$, mio-inositol (100 $\left.\mathrm{mg} \mathrm{L}{ }^{-1}\right)$, ágar $\left(7 \mathrm{~g} \mathrm{~L}^{-1}\right)$ e BAP $(0,44 \mathrm{mM})$.

$\mathrm{Na}$ etapa experimental, empregou-se meio MS, com concentrações de nutrientes minerais e vitaminas reduzidas à metade, suplementado com sacarose $\left(30 \mathrm{~g} \mathrm{~L}^{-1}\right)$, mioinositol (100mg L $\left.\mathrm{m}^{-1}\right)$ e ágar $\left(7 \mathrm{~g} \mathrm{~L}^{-1}\right) . \mathrm{O}$ pH foi ajustado para 5,8 , antes da adição do ágar, sendo a esterilização realizada por autoclavagem a $120^{\circ} \mathrm{C}$ e $1,0 \mathrm{kgf} . \mathrm{m}^{-2}$ de pressão, durante 15 minutos.
Utilizaram-se frascos de vidro com capacidade para $250 \mathrm{~mL}$, contendo $30 \mathrm{~mL}$ de meio de cultura e tampados com tampa de polipropileno modelo Garra 63â (Embasan). A sala de crescimento, durante os experimentos, foi mantida com temperatura de $24 \pm 2{ }^{\circ} \mathrm{C}$, fotoperíodo de 14 horas e densidade de fluxo luminoso de $40 \mu \mathrm{mol} . \mathrm{cm}^{-2} \cdot \mathrm{s}^{-1}$.

Os tratamentos utilizados foram 0,$0 ; 0,44 ; 1,78 ; 3,08$ e 4,44 mM de BAP.

O delineamento experimental utilizado nos experimentos foi inteiramente casualizado com cinco repetições, constituídos por cinco explantes cada. A avaliação foi realizada após 46 dias e os parâmetros avaliados foram: número total de brotações e número e altura de brotações maiores que três a quatro milímetros. Para análise dos dados foi utilizado o programa estatístico Statistica (STATSOFT, 1998), onde foi realizada a Análise de Variação seguida de Análise de Regressão Polinomial.

\section{RESULTADOS E DISCUSSÃO}

O número total de brotações e o número e altura de brotações superiores a $3 \mathrm{~mm}$ para as cultivares foi significativamente influenciado pelas diferentes concentrações de BAP, empregadas no meio de cultura.

Na Figura 1, observam-se os resultados de número total de brotações para as três cultivares. Para a cultivar Optimara Akemi, o número total de brotações aumenta até 1,78 mM de BAP. Já para Optimara Miki foi obtido com uma concentração intermediária entre 1,78 e 3,08 mM de BAP. Para Optimara Maki, o número de brotações aumenta até 3,08 $\mathrm{mM}$ de BAP.

Na Figura 2, constata-se o resultado do número de brotações maiores que três milímetros. O máximo de resposta, para Optimara Akemi, foi observado com a utilização de 1,78 mM. Para Optimara Miki, o maior número de brotações foi obtido com uma concentração intermediária entre 1,78 e 3,08 mM de BAP. Por outro lado, a concentração de $4,44 \mathrm{mM}$ proporcionou o maior número de brotações para Optimara Maki.

As concentrações de BAP para obtenção de uma maior taxa de multiplicação dessas cultivares se aproximam de 2,22 mM de BAP, valor recomendado por Tombolato et al. (1998), para multiplicação de violeta-africana a partir de brotações.

A concentração de BAP para a obtenção do maior número total de brotações e de brotações superiores a 3 $\mathrm{mm}$, assim como os valores máximos obtidos, variaram com o genótipo. Esse tipo de resultado é observado com frequiência quando se trabalha com mais de uma cultivar, pois o potencial de regeneração de cada uma delas é 


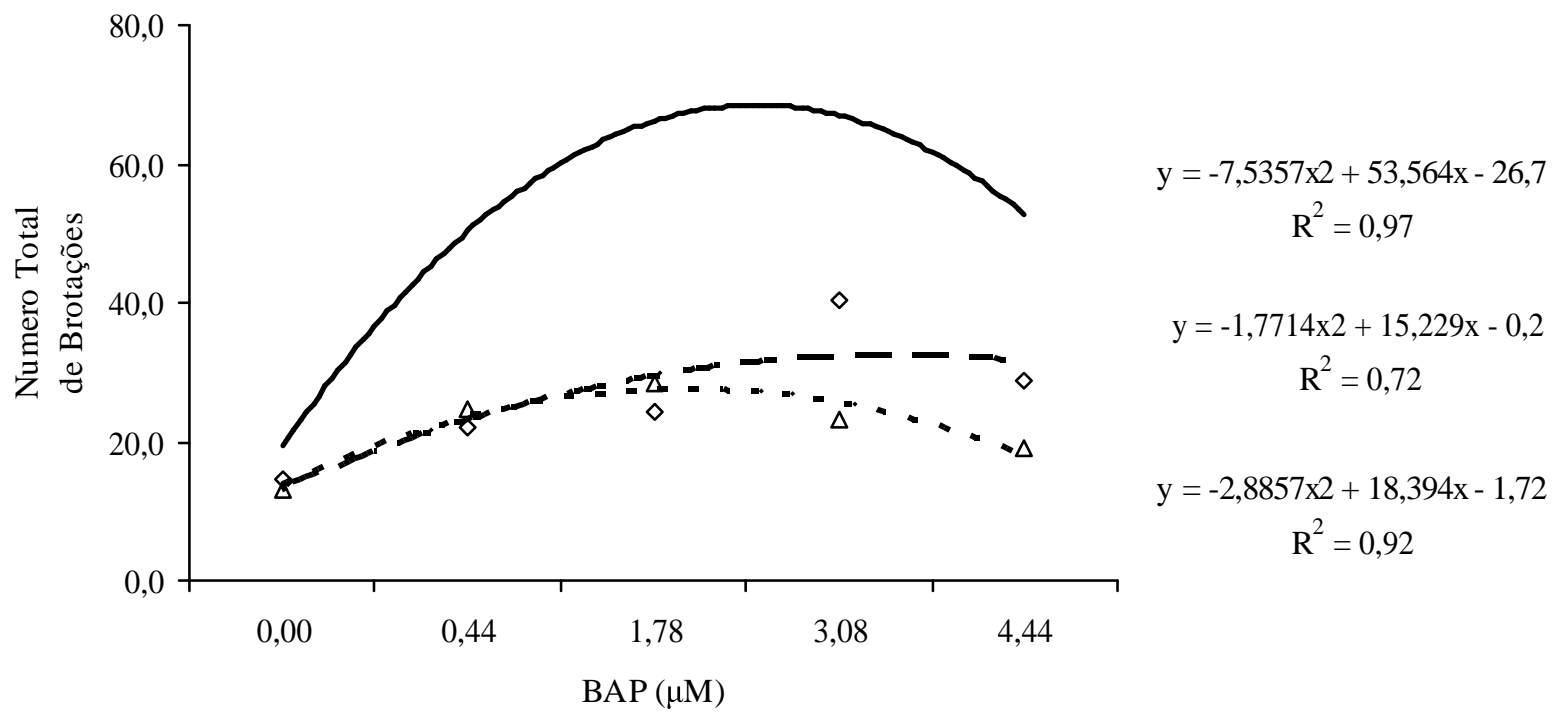

Polinômio (O.Miki) - - Polinômio (O.Maki) - - - - Polinômio (O.Akemi)

FIGURA 1 - Número total de brotações obtidas na multiplicação in vitro de violeta-africana, cultivares Optimara Miki, Optimara Maki e Optimara Akemi, em função de diferentes concentrações de BAP.

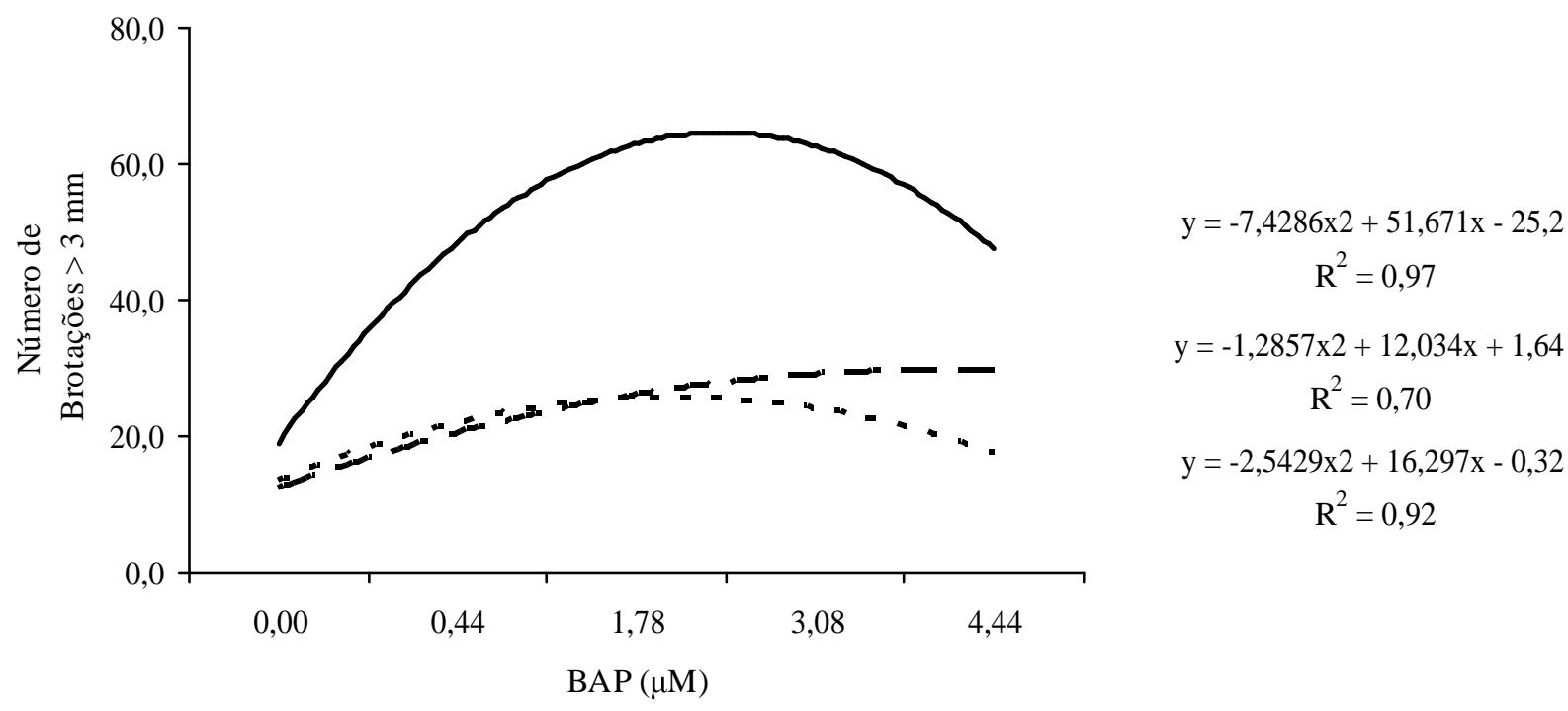

FIGURA 2 - Número de brotações maiores que $3 \mathrm{~mm}$ obtidas na multiplicação in vitro de culturas de violeta-africana, cultivares Optimara Miki, Optimara Maki e Optimara Akemi, em função de diferentes concentrações de BAP.

determinado geneticamente e sua expressão depende de fatores externos, como é o caso dos reguladores de crescimento (BARTISH \& KORKHOVOI, 1997; KORBAN et al., 1992).
A Figura 3, observa-se a altura de brotações maiores que três milímetros, na presença de diferentes concentrações de BAP. Os maiores valores de altura de brotações foram obtidos no meio sem adição de BAP. 


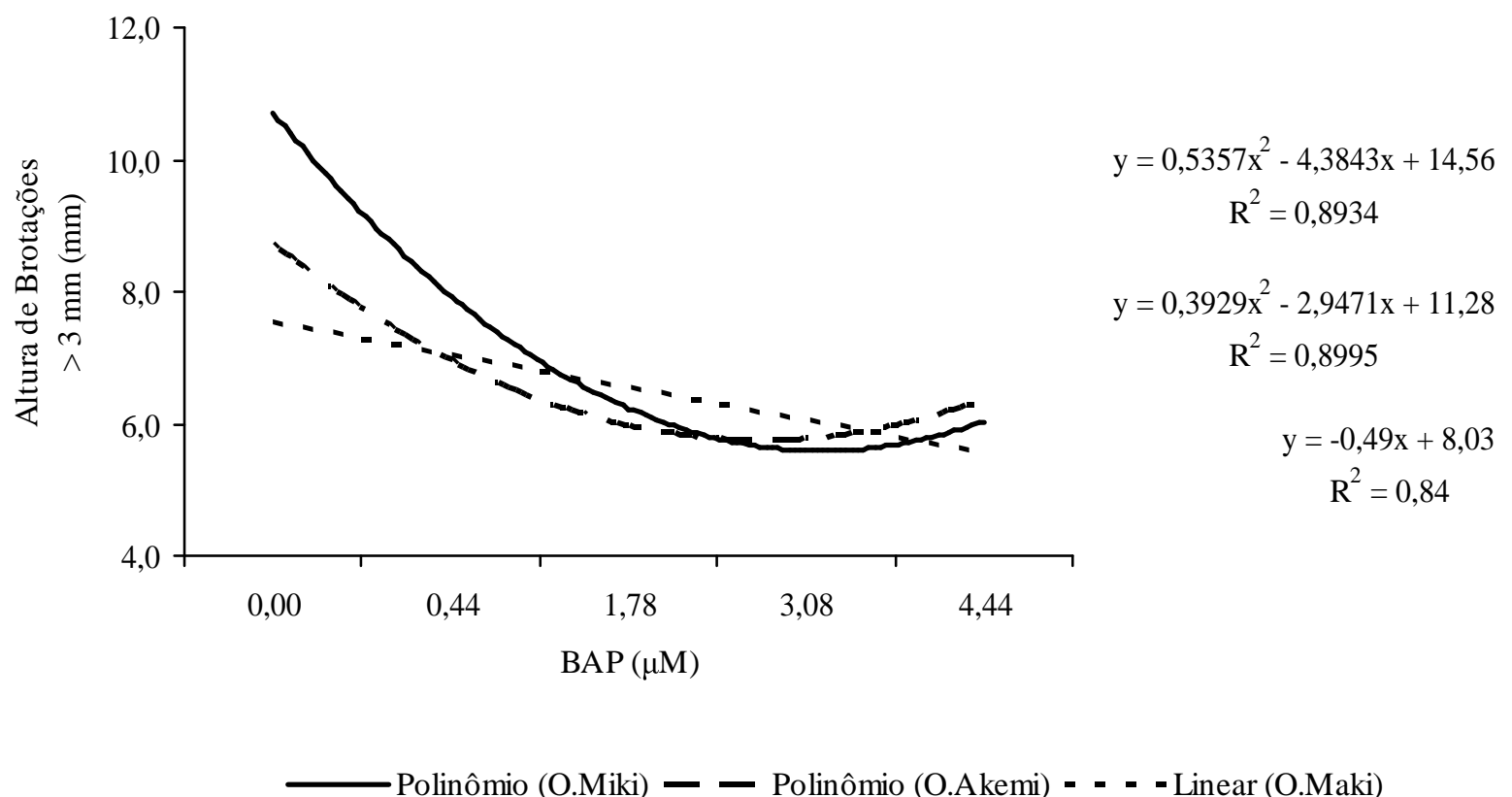

FIGURA 3 - Altura de brotações maiores que $3 \mathrm{~mm}$ obtidas na multiplicação in vitro de culturas de violeta-africana, cultivares Optimara Miki, Optimara Maki e Optimara Akemi, em função de diferentes concentrações de BAP.

O aumento no número de brotações e a redução na altura delas, com o incremento na concentração de BAP, são características da ação das citocininas no desenvolvimento da parte aérea das plantas (GOUSSARD, 1981), pois as citocininas induzem grupos de células responsivas, existentes no explante a se multiplicarem e a formarem brotações (KERBAUY, 1998). O incremento na concentração de BAP ativa um maior número desses grupos de células.

Esse mesmo incremento de BAP pode reduzir a altura de brotações por causa da utilização dos nutrientes disponíveis no meio para o desenvolvimento de um maior número de brotações, o que reduziria a disponibilidade deles para cada uma das brotações e, conseqüentemente, resultaria numa menor altura de brotações. As citocininas inibem o processo de alongamento de caules, interferindo no processo de alongamento da parede celular, mediada por auxinas e giberelinas (TAIZ \& ZEIGER, 2004).

A presença de calo nos três genótipos só foi verificada na multiplicação em concentrações superiores a 1,78 mM de BAP. Por outro lado, a formação de raízes foi observada apenas no tratamento sem BAP ou com este regulador na concentração de $0,44 \mathrm{mM}$.
A formação de calos com o aumento da concentração de BAP é relatada em trabalhos com violetaafricana (CASSELS et al., 1986) e com outras espécies, como Batata-doce e Crisântemo (ALVES et al., 1992; OLIVEIRA et al., 1995). O calo se forma com o aumento excessivo da concentração de reguladores de crescimento no meio de cultura. As concentrações mais elevadas de BAP inibiram a formação de raízes, uma vez que as citocininas, como é o caso do BAP, costumam induzir a regeneração de brotações e inibir o desenvolvimento do sistema radicular (GRATTAPAGLIA \& MACHADO, 1998).

\section{CONCLUSÕES}

Com base nos resultados apresentados, pode-se concluir que:

Para cada cultivar de violeta-africana existe uma concentração mais adequada de BAP, para obtenção da maior taxa de multiplicação;

As maiores taxas de multiplicação de violeta africana são obtidas com a adição de BAP, ao meio de cultura, na faixa de concentração entre 1,78 e 4,44 mM. 


\section{REFERÊNCIAS BIBLIOGRÁFICAS}

ALVES, J. M. C.; PINTO, J. E. B. P.; BARBOSA, M. H. P.; PINTO, C. A. B. P. Efeito da inibição correlativa e reguladores de crescimento na repicagem de plântulas de batata-doce (Ipomea batatais (L:) Lam) obtidas através da cultura de meristemas. Ciência e Prática, Lavras, v. 16, n. 3, p. 349-357, 1992.

BARTISH, I. V.; KORKHOVOI, V. I. The composition of nutrient medium and efficiency of shoot induction in vitro from apple leaf explants. Russian Journal of Plant Physiology, Russian, v. 44, n. 3, p. 440-444, 1997.

CALDAS, L. S.; HARIDASAN, P.; FERREIRA, M. E. Meios nutritivos. In: TORRES, A. L.; CALDAS, L. S.; BUSO, J. A. (Eds.). Cultura de tecidos e transformação genética de plantas. Brasília, DF: ASCTP/Embrapa-CNPQ, 1998. p. 89164.

CASSELS, A. C.; PLUNKETT, A.; KELLEHER, D. Screening of Saintpaulia ionantha Wendl. cultivars for caulogenetic potencial based on the in vitro responses of Young axenic leaves on auxin and cytokin factorial media. Scientia Horticulturae, Amsterdam, n. 30, p. 151157, 1986.

DORNELLES, L. T.; PETERS, J. A. Regeneração de plantas a partir de panículas imaturas de arroz (Oryza sativa L.). Acta Botânica Brasileira, Porto Alegre, v. 6, n. 2, p. 97 104, 1993.

GOUSSARD, P. G. Effects of cytokinins on elongation, proliferation and total mass shoot derived from shoot apices of grapevine cultured in vitro. Vitis, [S.1.], n. 20, p. 228-234, 1981.

GRATTAPAGLIA, D.; MACHADO, M. A. Micropropagação. In: TORRES, A. L.; CALDAS, L. S.; BUSO, J. A. (Eds.). Cultura de tecidos e transformação genética de plantas. Brasília, DF: ASCTP/Embrapa-CNPH, 1998. p. 183-260.

HARTMANN, H. T.; KOFRANEK, A. M.; RUBATZKY, V. E.; FLOCKER, W. J. Plant science: growth, development and utilization of cultivated plants. 2. ed. New Jersey: Regents; Prentice Hall, 1988. 674 p.
HUGHES, K. W. Introduction. In: HUGHES, K. W.; HENKE, R.; CONSTANTIN, M. Propagation of higher plants through tissue culture: a brindge between research and application. In: INTERNACIONAL SYMPOSIUM HELD AT THE UNIVERSITY OF TENNESSEE, 1978, Knoxville. Proceedings... Knoxville: United States Department of Energy, 1978. p. 85-86.

KERBAUY, G. B. Competência e determinação celular em culturas de células e tecidos de plantas. In: TORRES, A. L.; CALDAS, L. S.; BUSO, J. A. (Eds.). Cultura de tecidos e transformação genética de plantas. Brasília, DF: ASCTP/ Embrapa-CNPH, 1998. v. 2, p. 519-531.

KORBAN, S. S.; O'CONNOR, P. A.; ELOBEIDY, A. Effect of thidiazuron, naphthaleneacetic acid, dark incubation, and genotype on shot organogenesis from Malus leaves. Journal of Horticultural Science, London, v. 67, n. 3, p. 341-349, 1992.

MACIEL, A. L. R.; SILVA, A. B.; PASQUAL, M. Aclimatização de plantas de violeta africana (Saintpaulia ionantha Wendl.) obtidas in vitro: efeitos do substrato. Ciência e Agrotecnologia, Lavras, v. 24, n. 1, p. 9-12, jan./ mar. 2000

MURASHIGE, T.; SKOOG, F. A revised medium for rapid growth and bioassays with tobacco tissue cultures. Physiologia Plantarum, Copenhagen, v. 15, p. 473-497, 1962.

OLIVEIRA, P. D. de; PASQUAL, M.; PAIVA, R. Efeito de diferentes reguladores de crescimento sobre a proliferação in vitro de brotos de crisântemo (Dendranthema grandiflora Tzvelev.). Ciência e Prática, Lavras, v. 19, n. 4, p. 397-408, 1995.

STATSOFT.STATISTICA for Windows: computer program manual. Tulsa, 1998.

SUNPUI, W.; KANCHANAPOOM, K. Plant regeneration from petiole and leaf of African violet. (Saintpaulia ionantha Wendl.) cultured in vitro. Songklanakarin Journal Science Technology, [S.1.], v. 24, n. 3, p. 357-364, 2002.

TAIZ, L.; ZEIGER, E. Fisiologia vegetal. 3. ed. Porto Alegre: Artmed, 2004. 719 p. 
TAKEBAYASHI, S. S. G. Propagação “in vitro" de violeta africana (Saintapaulia ionantha Wendl.). In: CONGRESSO BRASILEIRO DE FLORICULTURA E PLANTAS ORNAMENTAIS, 6 ., 1987, Campinas. Anais... Campinas: Sociedade Brasileira de Floricultura e Plantas Ornamentais, 1987. p. 122-127.

TOMBOLATO, A. F. C.; CASTRO, C. E. F.; MATTHEUS, L. A. F.; TAMADA, E. T. Violeta africana. 4. ed. Campinas: Instituto Agronômico, 1987. (Boletim técnico, 200).
TOMBOLATO, A. F. C.; TAKEBAYASHI, S. S. G.; TAMADA, E. T.; FEITOSA, C. T. Cultivo comercial de violeta-africana. Campinas: Instituto Agronômico, 1995. 16 p. (Boletim técnico, 140).

TOMBOLATO, A. F. C.; TAKEBAYASHI, S. S. G.; TAMADA, E. T.; FEITOSA, C. T. Violeta-africana (Saintpaulia ionantha Wendl.). In: TOMBOLATO, A. F. C.; COSTA, A. M. M. Micropropagação de plantas ornamentais. Campinas: Instituto Agronômico, 1998. 72 p. (Boletim técnico, 174). 